\title{
Impaired Executive Function by Interictal Epileptiform Discharges in Patients with Idiopathic Generalized Epilepsy
}

\section{Jiang Yubao*, Wu Jiaonan, Wang Yu, Zhou Nong and Wang Kai}

Department of Neurology, The First Affiliated Hospital of Anhui Medical University, Anhui Sheng, China

*Corresponding author: Jiang Yubao, Department of Neurology, The First Affiliated Hospital of Anhui Medical University, Anhui Sheng, China, Tel: +86-551-62923704; E-mail: jiangyubao1982@126.com, wangkai1964@126.com

Rec date: Apr 07, 2017; Acc date: Apr 21, 2017; Pub date: Apr 27, 2017

Copyright: (c) 2017 Yubao J, et al. This is an open-access article distributed under the terms of the Creative Commons Attribution License, which permits unrestricted use, distribution, and reproduction in any medium, provided the original author and source are credited.

\begin{abstract}
Objective: Many patients with Idiopathic Generalized Epilepsy (IGE) exhibit cognitive deficits. Interictal Epileptiform Discharges (IEDs) may contribute to cognitive impairment in epilepsy; however, the relationship between IEDs and cognitive impairment is unclear.

Methods: In this study, we analysed executive function in three groups: IGE patients with IEDs, IGE patients without IEDs and healthy controls. Executive function was assessed using the Stroop Test, the Verbal Fluency Test, the Digit Span Test and Wisconsin Card-Sorting Test.

Results: The IGE patients with IEDs performed worse on executive function tests compared with patients without IEDs. Furthermore, the IGE patients without IEDs performed worse compared with healthy controls. There were significant differences between the three groups in performance on the Stroop Test, the Digit Span Test (forward and backward), Verbal Fluency Test (animals, fruits) and the subscales of WCST (Categories Completed, Correct Response, Total Errors and Preservative Errors).

Conclusion: These results suggest that executive function in patients with IGE is impaired and is further impaired by IEDs. Future studies should determine whether well-controlled patients with IGE could benefit from antiepileptic treatment.
\end{abstract}

Keywords: Sexecutive function; Interictal Epileptiform Discharges (IED); Idiopathic Generalized Epilepsy (IGE); Epilepsy; Cognition

\section{Introduction}

Epilepsy is a common brain disorder that is characterized by recurrent and spontaneous seizures that result from abnormal and excessive synchronization of neuronal activity. Epileptiform discharges are abnormal neuronal discharges seen on Electroencephalogram (EEG) as a result of transient synchronous depolarisation of neurons [1]. Findings from published work suggest that these discharges are not mere biomarkers of epilepsy but have important behavioural and cognitive consequences [2-4]. Niemann et al. established an independent relationship between cognitive impairment and the percentage of epileptiform discharges for a large number of factors such as the duration of epilepsy and the aetiology [5]. Evidence suggests that there is a relationship between epileptiform discharges and both learning difficulties and behavioural regression [6]. Epileptiform discharges not accompanied by obvious clinical events are generally regarded as subclinical or interictal. Investigations have confirmed the occurrence of cognitive deficits during Interictal Epileptiform Discharges (IEDs) [4,7]. Epileptiform discharges can result in Transitory Cognitive Impairment (TCI), with the type of deficit dependent on where in the cortex the Epileptiform discharges arises [8]. Furthermore, disruption of sleep architecture by epileptiform discharges may be an important factor contributing to cognitive impairment in children with epilepsy [9]. Although the most prominent effects of IEDs are attention and motor speed, transitory cognitive impairment is not simply inattention [10]. Focal discharges have been temporally linked to material-specific deficits, depending on the hemisphere and the particular brain region [11].

Executive functions are integral to higher level and complex cognitive processes and are thought to be responsible for the ability to plan and form abstract concepts and goals, carrying out goal-directed plans, adjust to changing demands and new instructions, and controlling attention, impulsivity, and emotions $[12,13]$. The Wisconsin Card Sorting Test is one of the most widely used executive tests [14]. Executive functions are important in everyday life and learning processes and are the most common cognitive domain affected in patients with temporal and extra temporal epilepsy [15].

Idiopathic Generalized Epilepsy (IGE) is typically associated with normal intelligence, but many patients' exhibit specific, frontal-lobe cognitive deficits [16-18]. A meta-analysis found that IGE patients demonstrated significantly lower scores on tests across all cognitive factor-domains except visual-spatial abilities [3] and increasing seizure frequency was significantly associated with worse outcomes [19]. Epilepsy is not understood as a disorder affecting one discrete brain region but as a disorder of widespread brain networks [20]. Although the neuropsychological and behavioural correlates of IGEs are less studied compared to temporal lobe epilepsy, compelling evidence implicates localized frontal lobe dysfunction in some IGE syndromes $[21,22]$. In this study, we investigated executive function in patients with IGE to determine the relationship between IEDs and executive function. 


\section{Materials and Methods}

\section{Patients}

All patients evaluated in the epilepsy specialist clinic of the First Affiliated Hospital of Anhui Medical University in 2014 were considered for participation in the present study. A total of 38 righthanded patients (19 males and 19 females) with IGE met the criteria and agreed to participate. All patients were seizure free for at least half a year. To be included in the study, patients had to: (a) Have been diagnosed with IGE as defined by the Commission on Classification and Terminology of the International League against Epilepsy [23]; (b) Have a normal cognitive ability, as determined by MoCA (Montreal Cognitive Assessment, patients with MoCA scores below 26 were excluded); (c) Have more than 5 years of education; (d) Have normal or corrected vision; and (e) Have the ability to understand the procedures of the experiment. Patients with evidence of other neurological or psychiatric disorders, as determined by a medical history, physical examination or neuroimaging, were excluded. All patients were interviewed during $24 \mathrm{~h}$ ambulatory EEG recording (including hyperventilation and all EEG recordings captured sleep). Medical records were also reviewed to obtain their demographic(gender, age, education) and clinical information(age at seizure onset, disease duration, seizure free duration, history of antiepileptic drug therapy and current dosages, previous EEG findings and neuroimaging findings). Based on the results of the EEG monitoring, the patients were divided into two groups: patients without IEDs and patients with IEDs. In group without IEDs, 12 patients were juvenile myoclonic epilepsy, 2 patients were childhood absence epilepsy and 1 patient was GTCS only. In group with IEDs, 15 patients were juvenile myoclonic epilepsy, 2 patients were childhood absence epilepsy, 3 patients were juvenile absence epilepsy, 2 patients were epilepsy with myoclonic absences and 1 patient was GTCS (generalized tonic-clonic seizures) only.

Additionally, we included a group of Healthy Controls (HC), which included 24 participants ( 9 males and 15 females) who were matched to the patient group on age, gender and education.

This study was approved by the ethics committee of Anhui medical university and all participants provided written informed consent to participate in the study.

\section{Background tests}

All patients completed the MoCA Beijing version. The Beck Depression Inventory (BDI, translated into Chinese) and Hamilton Anxiety Scale (HAMA, translated into Chinese) were administered to obtain measurements of depressive and anxiety symptoms in both the patients with IGE and the healthy controls.

\section{Executive function tests}

Executive function was assessed using the Stroop Test, the Verbal Fluency Test (using animal, fruit and word categories), the Digit Span Test (forward and backward) and the Wisconsin Card-Sorting Test [24]. All patients completed executive function assessment during the $24 \mathrm{~h}$ ambulatory EEG recording.

The Stroop Test evaluates the ease with which a person can maintain a goal in mind and suppress a habitual response in favour of a less familiar one. It also assesses selective attention, susceptibility to interference and cognitive flexibility. The difference (in seconds) between the execution time of the third (words) and the first (colours) tasks was evaluated [25].

The Verbal Fluency Test (using semantic categories of animals and fruits, and phonemic categories) evaluates the spontaneous production of words under restricted search conditions. The generation of words belonging to a certain category within $1 \mathrm{~min}$ is used to assess verbal association fluency and mental retrieval from long-term memory [26].

In the Digit Span (DS) Test (forward and backward), a string of digital numbers is presented beginning with length of 3 digits forward or 2 digits backward. In the DS forward, the participant must listen to a digit span at a speed of one digit per second and repeat it forward. The DS backward follows the same procedure as the DS forward except the participant must repeat the span backward. Two trials were presented at each length. The test was halted when the participant failed to recall both sequences at a single sequence length [27].

The Wisconsin Card-Sorting Test (WCST) requires participants to match cards to one of four target cards. The examinee was not told how to match the cards but was informed if their particular match on each response was correct or incorrect. The sorting principles include colour, shape and number. The sorting principles are changed during the course of the test and the examinee had to use examiner feedback to arrive at a correct solution. The 128-card, hand-administered version of WCST was used. Scores used for analysis were the number of categories completed, correct responses, preservative responses and preservative errors [24].

\section{Statistical analysis}

Statistical analyses were performed using SPSS version 20.0 for Windows. A Chi-square test was performed for the variable of gender. Non-parametric statistics (Kruskal-Wallis test) were performance for the variables of age, education, MoCA, BDI and HAMA. The variables of age at seizure onset, disease duration, seizure-free time, and the daily dose of Valproic Acid (VPA) and Lamotrigine (LTG) were assessed using non-parametric statistics (Mann-Whitney test). An Analysis of Covariance (ANCOVA) was used to compare the variables of the Stroop Test, Digital Span Test (forward and backward), Verbal Fluency Test and WCST across the three groups and the daily dose of VPA were used as a covariant. Pairwise comparisons were tested using the Least Significance Test. A $p<0.05$ was considered to be statistically significant.

\section{Results}

\section{Demographic variables and background tests}

All IGE patients were being treated with Antiepileptic Drugs (AEDs) and were well controlled. All patients were seizure free for at least half a year. Of the IGE patients in this study, 20 patients used VPA (sodium valproate, produced by Sanofi Co. Ltd.) only, 16 patients used LTG (lamotrigen, produced by GSK Co. Ltd.) only and 2 patients used both VPA and LTG. The group without IEDs contained a total of 15 patients (8 males and 7 females); 8 of those patients used VPA only and 7 patients used LTG only. The group with IEDs contained a total of 23 patients (11 males and 12 females); 12 of those patients used VPA only, 9 patients used LTG only and 2 patients used both VPA and LTG. The healthy control group (HC) included 24 participants (11 males and 13 females). 
Citation: Yubao J, Jiaonan W, Yu W, Nong Z, Kai W (2017) Impaired Executive Function by Interictal Epileptiform Discharges in Patients with Idiopathic Generalized Epilepsy. J Epilepsy 3: 118. doi:10.4172/2472-0895.1000118

Page 3 of 6

The number of male and female participants was equal across the three groups. We found no significant differences in age, education, MoCA scores, BDI scores and HAMA scores between the three groups. There was also no significant difference in the age at seizure onset, disease duration, seizure-free time and the average daily dose of LTG between the two IGE groups. The IGE group with IEDs had a higher average daily dose of VPA compared to the group of IGE patients without IEDs. The details are shown in Table 1.

\begin{tabular}{|c|c|c|c|c|}
\hline & $\begin{array}{l}\text { With } \\
\text { IEDs }\end{array}$ & $\begin{array}{l}\text { Without } \\
\text { IEDs }\end{array}$ & $\mathrm{HC}$ & P-Value \\
\hline $\mathrm{N}$ & 23 & 15 & 24 & \\
\hline Gender(Male/Female) & 11-Dec & 08-Jul & Nov-13 & $\begin{array}{l}X^{2}=0.213 \\
p=0.899\end{array}$ \\
\hline Age(years) & $\begin{array}{l}17.87 \pm \\
5.27\end{array}$ & $\begin{array}{l}20.53 \quad \pm \\
6.05\end{array}$ & $\begin{array}{l}18.46 \pm \\
6.44\end{array}$ & $\begin{array}{l}X^{2}=2.595 \\
d f=2, p=0.273\end{array}$ \\
\hline Education(years) & $\begin{array}{l}9.26 \\
2.85\end{array}$ & $\begin{array}{l}11.00 \quad \pm \\
3.32\end{array}$ & $\begin{array}{l}10.13 \pm \\
3.25\end{array}$ & $\begin{array}{l}X^{2}=2.893 \\
d f=2, p=0.235\end{array}$ \\
\hline MoCA & $\begin{array}{l}27.39 \pm \\
1.07\end{array}$ & $\begin{array}{ll}27.20 & \pm \\
1.52 & \end{array}$ & $\begin{array}{l}28.25 \pm \\
1.42\end{array}$ & $\begin{array}{l}X^{2}=5.841 \\
d f=2, p=0.054\end{array}$ \\
\hline BDI & $\begin{array}{ll}6.14 & \pm \\
5.83\end{array}$ & $5.46 \pm 4.68$ & $\begin{array}{l}2.74 \quad \pm \\
3.49\end{array}$ & $\begin{array}{l}X^{2}=4.680 \\
d f=2, p=0.096\end{array}$ \\
\hline HAMA & $\begin{array}{l}4.36 \\
4.66\end{array}$ & $3.21 \pm 3.40$ & $\begin{array}{l}2.21 \pm \\
2.99\end{array}$ & $\begin{array}{l}X^{2}=3.877 \\
d f=2, p=0.144\end{array}$ \\
\hline Age at seizure onset & $\begin{array}{l}12.10 \pm \\
4.82\end{array}$ & $\begin{array}{ll}15.38 & \pm \\
7.20 & \end{array}$ & - & $\begin{array}{l}Z=1.436 \\
p=0.153\end{array}$ \\
\hline Disease duration(years) & $\begin{array}{ll}5.78 & \pm \\
4.33 & \end{array}$ & $5.15 \pm 4.07$ & - & $\begin{array}{l}Z=0.329 \\
p=0.746\end{array}$ \\
\hline Seizure Free(years) & $\begin{array}{l}2.46 \\
2.03\end{array}$ & $3.40 \pm 2.83$ & - & $\begin{array}{l}Z=1.389 \\
p=0.172\end{array}$ \\
\hline Dose of VPA (g/day) & $\begin{array}{l}0.982 \pm \\
0.229\end{array}$ & $\begin{array}{l}0.718 \\
0.282\end{array}$ & - & $\begin{array}{l}Z=2.134 \\
p=0.033^{*}\end{array}$ \\
\hline Dose of LTG (g/day) & $\begin{array}{l}0.118 \pm \\
0.040\end{array}$ & $\begin{array}{l}0.100 \\
0.029\end{array}$ & - & $\begin{array}{l}Z=0.986 \\
p=0.324\end{array}$ \\
\hline
\end{tabular}

Table 1: Demographic variables and performance on the background tests $\left({ }^{*} \mathrm{P}<0.05\right)$.

\section{Performance on the executive function tests}

The IGE patients with IEDs performed worse on executive function tests compared with patients without IEDs. Furthermore, the IGE patients without IEDs performed worse compared with the healthy controls. There were significant differences between the three groups in performance on the Stroop Test, the Digit Span Test (forward and backward), Verbal Fluency Test (animals, fruits) and the subscales of WCST (Categories Completed, Correct Response and Preservative Errors). There were no significant differences between the groups on the Verbal Fluency Test (words) and the subscales of WCST (Preservative Responses). In addition, the daily dosage of VPA did not effect the differences in executive function observed between the three groups. Considering the wide age range and ongoing brain development in all participants, age were also included as a covariate in the analyses and found that age effect the differences in Verbal Fluency Test observed between the three groups. The details are shown in Table 2 and the results of the post-hoc tests are shown in Figure 1.

\begin{tabular}{|c|c|c|c|c|c|}
\hline & $\begin{array}{l}\text { With } \\
\text { IEDs }\end{array}$ & $\begin{array}{l}\text { Without } \\
\text { IEDs }\end{array}$ & $\mathrm{HC}$ & P-Value & $\begin{array}{l}\text { VPA dose } \\
\text { effect }\end{array}$ \\
\hline Strop & $\begin{array}{l}17.02 \\
\pm \\
12.61\end{array}$ & $\begin{array}{l}10.54 \quad \pm \\
8.36\end{array}$ & $\begin{array}{l}6.39 \pm \\
4.82\end{array}$ & $\begin{array}{l}F=3.555 \\
d f=2 \\
p=0.036^{*}\end{array}$ & $\begin{array}{l}F=0.055 \\
d f=1 \\
p=0.815\end{array}$ \\
\hline DS(Forward) & $\begin{array}{l}7.48 \pm \\
1.08\end{array}$ & $7.93 \pm 0.62$ & $\begin{array}{l}9.29 \pm \\
1.16\end{array}$ & $\begin{array}{l}F=5.417 \\
d f=2 \\
p=0.007^{* *}\end{array}$ & $\begin{array}{l}F=1.122 \\
d f=1 \\
p=0.294\end{array}$ \\
\hline DS(Backward) & $\begin{array}{l}5.57 \pm \\
1.41\end{array}$ & $6.00 \pm 1.41$ & $\begin{array}{l}7.18 \pm \\
1.63\end{array}$ & $\begin{array}{l}F=6.249 \\
d f=2 \\
p=0.004^{* *}\end{array}$ & $\begin{array}{l}F=0.884, \\
d f=1 \\
p=0.351\end{array}$ \\
\hline VFT(Animals) & $\begin{array}{l}11.00 \pm \\
2.71\end{array}$ & $\begin{array}{l}13.00 \quad \pm \\
6.13\end{array}$ & $\begin{array}{l}22.24 \\
\pm 6.38\end{array}$ & $\begin{array}{l}F=15.788 \\
d f=2, \\
p=0.000^{* *}\end{array}$ & $\begin{array}{l}F=0.827 \\
d f=1 \\
p=0.367\end{array}$ \\
\hline VFT(Fruits) & $\begin{array}{l}9.91 \pm \\
0.90\end{array}$ & $\begin{array}{l}11.29 \quad \pm \\
3.58\end{array}$ & $\begin{array}{l}14.35 \\
\pm 3.77\end{array}$ & $\begin{array}{l}F=5.693 \\
d f=2 \\
p=0.006^{* *}\end{array}$ & $\begin{array}{l}F=1.663 \\
d f=1 \\
p=0.203\end{array}$ \\
\hline VFT(words) & $\begin{array}{l}5.00 \pm \\
2.34\end{array}$ & $6.29 \pm 2.81$ & $\begin{array}{l}7.71 \pm \\
4.88\end{array}$ & $\begin{array}{l}F=1.448, \\
d f=2, \\
p=0.245\end{array}$ & $\begin{array}{l}F=0.436 \\
d f=1 \\
p=0.512\end{array}$ \\
\hline \multicolumn{6}{|l|}{ WCST } \\
\hline $\begin{array}{l}\text { Categories } \\
\text { Completed }\end{array}$ & $\begin{array}{l}5.15 \pm \\
2.52\end{array}$ & $6.64 \pm 1.65$ & $\begin{array}{l}8.06 \pm \\
1.44\end{array}$ & $\begin{array}{l}F=8.377 \\
d f=2 \\
p=0.001^{\star \star}\end{array}$ & $\begin{array}{l}F=0.757 \\
d f=1 \\
p=0.388\end{array}$ \\
\hline Correct Response & $\begin{array}{l}86.6 \pm \\
15.10\end{array}$ & $\begin{array}{l}95.86 \quad \pm \\
8.76\end{array}$ & $\begin{array}{l}98.94 \\
\pm 5.60\end{array}$ & $\begin{array}{l}F=8.776 \\
d f=2 \\
p=0.000^{* *}\end{array}$ & $\begin{array}{l}F=3.603 \\
d f=1 \\
p=0.063\end{array}$ \\
\hline Total Errors & $\begin{array}{l}40.57 \\
\pm \\
15.76\end{array}$ & $\begin{array}{l}30.57 \\
9.74\end{array}$ & $\begin{array}{l}23.53 \\
\pm 7.73\end{array}$ & $\begin{array}{l}F=12.260 \\
d f=2, \\
p=0.000^{* *}\end{array}$ & $\begin{array}{l}F=3.035 \\
d f=1 \\
p=0.087\end{array}$ \\
\hline $\begin{array}{l}\text { Perseverative } \\
\text { Responses }\end{array}$ & $\begin{array}{l}45.39 \\
\pm \\
16.29\end{array}$ & $\begin{array}{l}39.43 \\
6.79\end{array}$ & $\begin{array}{l}41.82 \\
\pm 6.13\end{array}$ & $\begin{array}{l}F=1.879 \\
d f=2, \\
p=0.162\end{array}$ & $\begin{array}{l}F=2.077 \\
d f=1 \\
p=0.155\end{array}$ \\
\hline $\begin{array}{l}\text { Perseverative } \\
\text { Errors }\end{array}$ & $\begin{array}{l}23.43 \\
\pm \\
12.06\end{array}$ & $\begin{array}{l}15.36 \\
5.72\end{array}$ & $\begin{array}{l}15.71 \\
\pm 5.03\end{array}$ & $\begin{array}{l}F=4.425 \\
d f=2, \\
p=0.017^{* *}\end{array}$ & $\begin{array}{l}F=0.854 \\
d f=1 \\
p=0.359\end{array}$ \\
\hline
\end{tabular}

Table 2: Performance on the executive function tests (Mean \pm SD), DS: Digital Span; VFT: Verbal Fluency Test; WCST: Wisconsin CardSorting Test; ${ }^{*} \mathrm{P}<0.05 ;{ }^{* *} \mathrm{P}<0.01$. 


\section{Performance of executive function tests}

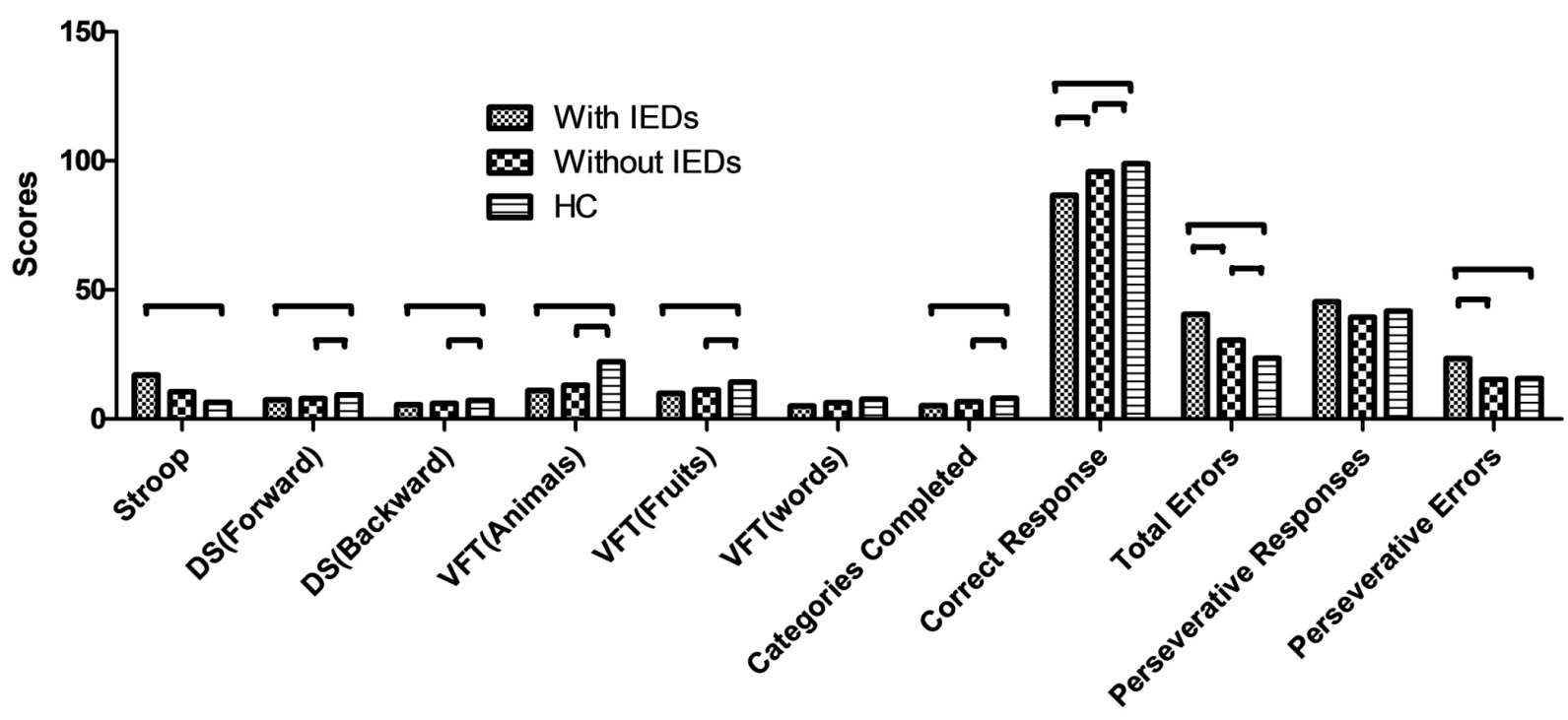

Figure 1: Performance on the executive function tests.

\section{Discussion}

In the present study, we found impaired executive function in patients with IGE, which is consistent with previous findings $[24,28]$. IGE Patients with IEDs performed worse in executive function than patients without IEDs. Given that the patients were well-controlled such that the two groups did not significantly differ with respect to the other variables, this difference is likely attributed to the IEDs.

IGE is characterized by bilateral synchronous epileptiform discharges on EEG and recurrent generalized seizures. Evidence from previous studies suggests that epileptiform activity is the dominant factor that inhibits specific brain areas. A higher spike-wave index during NREM (non-rapid eye movement) sleep is associated with impaired performance in the nonverbal task in patients with idiopathic epilepsies [29]. Tassinari and Rubboli suggested that focal spikes could disrupt cortical functions and produce TCI. The authors speculate that prolonged focal epileptic activity impairs neural processes and possibly the local plastic changes associated with learning and other cognitive functions [30]. Nicolai et al. reported that cognitive and behavioural problems are related to epileptiform discharges in children with BECTs (benign childhood epilepsy with centrotemporal spikes) [31]. In humans, IEDs recorded using depth electrodes implanted into the hippocampus showed a disruption in memory maintenance and retrieval, but not encoding [32]. These studies strengthen the argument that IEDs may contribute to cognitive impairment in epilepsy depending upon when and where they occur.

However, not all studies have found a relationship between epileptiform discharges or short seizures and cognitive impairment [33]. Studies have shown that simple motor tasks and other tasks with low information processing demand (i.e., tasks that do not require information processing of complex sets of information) are slightly or not affected by epileptiform discharges, whereas tasks with high information processing demand are considered to be more sensitive
[10,34]. In our study, executive function was assessed using the Stroop Test, the Verbal Fluency Test, the Digit Span Tests and the WCST, which have been used in several studies and have been demonstrated to be suitable to investigate executive function $[15,24,35]$.

Based on the causal relationship between epileptiform discharges and cognitive impairment, several studies have investigated whether treatment of IEDs can improve the cognitive and behavioural problems associated with IEDs. Treatment of subclinical epileptiform discharges in cerebral palsy patients without clinical epilepsy has been shown to improve their prognosis and quality of life [36-38]. Furthermore, suppression of IEDs has been found to improve behaviour only in patients who showed a significant decrease in either the frequency or duration of the discharges [39]. Children who showed a significant reduction in subclinical seizures after initiation of LTG also showed significant improvement in behaviour [40]. Uncontrolled reports and many preliminary randomized controlled trials of antiepileptic treatment for IEDs have suggested that suppression of discharges is associated with significant improvement in psychosocial function [41].

All commonly used AEDs have some effect on cognitive function, which may be substantial when crucial functions are involved [42]. For example, phenytoin may affect mental speed and phenobarbital may affect attention and memory. Evidence has shown that LTG has a cognitive-enhancing effect on attention [42]. A recent study demonstrated that the cognitive side effect profile of lacosamide is comparable to that of LTG and superior to that of topiramate, which was indicated by both subjective and objective measures [43]. VPA does not appear to impair cognition if sufficiently controlled for hyperammonemia [42]; however, studies have shown VPA can reduce spatial working memory and cell proliferation in the hippocampus [44]. These results support the idea that VPA may cause cognitive impairment by reducing neurogenesis within the hippocampus [44]. In this study, the average daily dose of LTG was similar between the two IGE groups, but the patients with IEDs had a higher average daily dose 
of VPA compared with the patients without IEDs; however, the daily dose of VPA was used as covariant in our analysis, and we found this difference did not affect our results. Therefore, the differences in executive function between the two groups (the patients with IEDs and the patients without IEDs) may be caused by the IEDs themselves.

Decisions on treatment in daily clinical practice partly depend on the question of whether the IEDs diminish cognitive function; however, official guidelines on the treatment of TCI in the presence of focal or generalized IEDs have not been established. A recent study found that the IED index of 10\% (a measurement that indicates if a spike or spike-wave complex occurs within $1 \mathrm{~s}$ of one page or $10 \mathrm{~s}$ ) is the minimum threshold for the negative effects of IEDs on cognitive performance in adult patients with epilepsy [45], which suggests that treatment of IEDs to improve cognition should be further examined. Although there is increasing evidence for an impact of IEDs on cognition, a consensus has not been reached for different populations (child or adult patients) or on different IED indexes (distribution or location). Therefore, future studies should include a large number of patients and placebo-controlled randomized trials to address these crucial questions.

Also this study has some limitations. Brain development is potential mediator to affect the cognitive function in patients with epilepsy [46]. Considering the wide age range and ongoing brain development in all participants, age were included as a covariate in the analyses and found that age affect the differences in Verbal Fluency Test observed between the three groups. The cognitive effect of brain development in patients with epilepsy should be discussed in our future studies.

\section{Conflict of Interest}

None of the authors has any conflict of interest to disclose. We confirm that we have read the Journal's position on issues involved in ethical publication and affirm that this report is consistent with those guidelines.

\section{Acknowledgements}

This work was supported by Natural Science grants to Y Wang (grant number: 81271444) from the National Natural Science Foundation of China

\section{References}

1. Prince DA, Connors BW (1986) Mechanisms of interictal epileptogenesis Adv Neurol 44: 275-299.

2. Nicolai J, Saskia E, Danielle PLJJGB, Arends J, Hendriksen J, et al. (2012) The cognitive effects of interictal epileptiform EEG discharges and short nonconvulsive epileptic seizures. Epilepsia 53: 1051-1059.

3. Loughman A, Bowden SC, Souza WD (2014) Cognitive functioning in idiopathic generalised epilepsies: a systematic review and meta-analysis. Neurosci Biobehav Rev 43: 20-34.

4. Aldenkamp AP, Beitler J, Arends JBAM, van der Linden I, Diepman L, et al. (2005) Acute effects of subclinical epileptiform EEG discharges on cognitive activation. Funct Neurol 20: 23-28.

5. Niemann H, Boenick HE, Schmidt RC, Ettlinger G (1985) Cognitive development in epilepsy: The relative influence of epileptic activity and brain damage. Eur Arch Psychiatry Neurol Sci 234: 399-403.

6. Tuchman RF, Rapin I (1997) Regression in pervasive developmental disorders: seizures and epileptiform electroencephalogram correlates. Pediatrics 99: 560-566.
7. Aarts JHP, Binnie CD, Smit AM, Wilkins AJ (1984) Selective cognitive impairment during focal and generalized epileptiform EEG activity. Brain 107: 293-308.

8. Holmes GL, Lenck-Santini PP (2006) Role of interictal epileptiform abnormalities in cognitive impairment. Epilepsy Behav 8: 504-515.

9. Chan S, Baldeweg T, Cross JH (2011) A role for sleep disruption in cognitive impairment in children with epilepsy. Epilepsy Behav 20: 435-440.

10. Binnie CD (2003) Cognitive impairment during epileptiform discharges: is it ever justifiable to treat the EEG? Lancet Neurol 2: 725-730.

11. Shewmon DA, Erwin RJ (1988) The effect of focal interictal spikes on perception and reaction time. II. Neuroanatomic specificity. Electroencephalogr Clin Neurophysiol 69: 338-352.

12. Stuss DT, Alexander MP (2000) Executive functions and the frontal lobes: a conceptual view. Psychol Res 63: 289-298.

13. Jurado MB, Rosselli M (2007) The elusive nature of executive functions: a review of our current understanding. Neuropsychol Rev 17: 213-233.

14. Grant DA, Berg EA (1948) A behavioral analysis of degree of reinforcement and ease of shifting to new responses in a Weigl-type cardsorting problem. J Exp Psychol 38: 404-411.

15. Rai VK, Shukla G, Afsar M, Poornima S, Pandey RM, et al. (2015) Memory, executive function and language function are similarly impaired in both temporal and extra temporal refractory epilepsy-A prospective study. Epilepsy Res 109: 72-80.

16. Devinsky O, Gershengorn J, Brown E (1997) Frontal functions in juvenile myoclonic epilepsy. Neuropsychiatry Neuropsychol Behav Neurol 10: 243-246.

17. Iqbal N, Caswell HL, Hare DJ, Pilkington O, Mercer S, et al. (2009) Neuropsychological profiles of patients with juvenile myoclonic epilepsy and their siblings: a preliminary controlled experimental video-EEG case series. Epilepsy Behav 14: 516-521.

18. Kim JH, Suh SI, Park SY, Seo WK, Koh IS, et al. (2012) Microstructural white matter abnormality and frontal cognitive dysfunctions in juvenile myoclonic epilepsy. Epilepsia 53: 1371-1378.

19. Gupta S, Kwan P, Faught E, Tsong W, Forsythe A, et al. (2016) Understanding the burden of idiopathic generalized epilepsy in the United States, Europe, and Brazil: An analysis from the National Health and Wellness Survey. Epilepsy Behav 55: 146-156.

20. Richardson M (2010) Current themes in neuroimaging of epilepsy: brain networks, dynamic phenomena, and clinical relevance. Clin Neurophysiol 121: 1153-1175.

21. Jiang Y, Hu Y, Wang Y, Zhou N, Zhu L, et al. (2014) Empathy and emotion recognition in patients with idiopathic generalized epilepsy. Epilepsy Behav 37: 139-144.

22. Chowdhury FA, Elwes RDC, Koutroumanidis M, Morris RG, Nashef L, et al. (2014) Impaired cognitive function in idiopathic generalized epilepsy and unaffected family members: an epilepsy endophenotype. Epilepsia 55: 835-840.

23. Bancaud J, Henriksen O, Rubio-Donnadieu F, Seino M, Dreifuss FE, et al. (1981) Proposal for revised clinical and electroencephalographic classification of epileptic seizures. From the Commission on Classification and Terminology of the International League Against Epilepsy. Epilepsia 22: 489-501.

24. Lima AB, Moreira F, Gomes MM, Maia-Filho H (2014) Clinical and neuropsychological assessment of executive function in a sample of children and adolescents with idiopathic epilepsy. Arq Neuropsiquiatr 72: 954-959.

25. Elst VW, Boxtel VMP, Breukelen VGJ, Jolles J (2006) The Stroop colorword test: influence of age, sex, and education; and normative data for a large sample across the adult age range. Assessment 13: 62-79.

26. Baldo JV, Shimamura AP, Delis DC, Kramer J, Kaplan E (2001) Verbal and design fluency in patients with frontal lobe lesions. J Int Neuropsychol Soc 7: 586-596. 
Citation: Yubao J, Jiaonan W, Yu W, Nong Z, Kai W (2017) Impaired Executive Function by Interictal Epileptiform Discharges in Patients with Idiopathic Generalized Epilepsy. J Epilepsy 3: 118. doi:10.4172/2472-0895.1000118

Page 6 of 6

27. Tamez E, Myerson J, Morris L, White DA, Baum C, et al. (2011) Assessing executive abilities following acute stroke with the trail making test and digit span. Behav Neurol 24: 177-185.

28. Gelziniene G, Jurkeviciene G, Marmiene V, Adomaitiene V, Endziniene $M$ (2011) Executive functions in adolescents with idiopathic generalized epilepsy. Medicina (Kaunas) 47: 313-319.

29. Galer S, Urbain C, Tiege XD, Emeriau M, Leproult R, et al. (2015) Impaired sleep-related consolidation of declarative memories in idiopathic focal epilepsies of childhood. Epilepsy Behav 43: 16-23.

30. Tassinari CA, Rubboli G (2006) Cognition and paroxysmal EEG activities: from a single spike to electrical status epilepticus during sleep. Epilepsia 47: 40-43

31. Nicolai J, Aldenkamp AP, Arends J, Weber JW, Vles JS (2006) Cognitive and behavioral effects of nocturnal epileptiform discharges in children with benign childhood epilepsy with centrotemporal spikes. Epilepsy Behav 8: 56-70.

32. Kleen JK, Scott RC, Holmes GL, Roberts DW, Rundle MM, et al. (2013) Hippocampal interictal epileptiform activity disrupts cognition in humans. Neurology 81: 18-24.

33. Aldenkamp AP, Arends J (2004) Effects of epileptiform EEG discharges on cognitive function: is the concept of "transient cognitive impairment" still valid? Epilepsy Behav 5: 25-34.

34. Tromp SC, Weber JW, Aldenkamp AP, Arends J, vander Linden I, et al. (2003) Relative influence of epileptic seizures and of epilepsy syndrome on cognitive function. J Child Neurol 18: 407-412.

35. Riccio C, Pliego J, Cohen M, Park Y (2015) Executive Function Performance for Children With Epilepsy Localized to the Frontal or Temporal Lobes. Appl Neuropsychol Child 4: 277-284

36. Jaseja H, Jaseja B, Badaya S, Tonpay P (2012) Treatment of interictal epileptiform discharges (IEDs) in patients with cerebral palsy for an improved prognostic outcome and quality of life: emerging evidence. Epilepsy Behav 25: 473.

37. Jaseja H (2007) Treatment of interictal epileptiform discharges in cerebral palsy patients without clinical epilepsy: hope for a better outcome in prognosis. Clin Neurol Neurosurg 109: 221-224.

38. Jaseja H (2007) Cerebral palsy: Interictal epileptiform discharges and cognitive impairment. Clin Neurol Neurosurg 109: 549-552.

39. Pressler RM, Robinson RO, Wilson GA, Binnie CD (2005) Treatment of interictal epileptiform discharges can improve behavior in children with behavioral problems and epilepsy. J Pediatr 146: 112-117.

40. Pressler RM, Binnie CD, Coleshill SG, Chorley GA, Robinson RO (2006) Effect of lamotrigine on cognition in children with epilepsy. Neurology 66: 1495-1499.

41. Garcia-Penas JJ (2011) Interictal epileptiform discharges and cognitive impairment in children. Rev Neurol 52: 43-52

42. Ijff DM, Aldenkamp AP (2013) Cognitive side-effects of antiepileptic drugs in children. Handb Clin Neurol 111: 707-718.

43. Helmstaedter C, Witt JA (2013) The longer-term cognitive effects of adjunctive antiepileptic treatment with lacosamide in comparison with lamotrigine and topiramate in a naturalistic outpatient setting. Epilepsy Behav 26: 182-187.

44. Umka J, Mustafa S, ElBeltagy M, Thorpe A, Latif L, et al. (2010) Valproic acid reduces spatial working memory and cell proliferation in the hippocampus. Neuroscience 166: 15-22.

45. Lv Y, Wang Z, Cui L, Ma D, Meng H (2013) Cognitive correlates of interictal epileptiform discharges in adult patients with epilepsy in China. Epilepsy Behav 29: 205-210.

46. Lin JJ, Mula M, Hermann BP (2012) Uncovering the neurobehavioural comorbidities of epilepsy over the lifespan. Lancet 380: 1180-1192. 